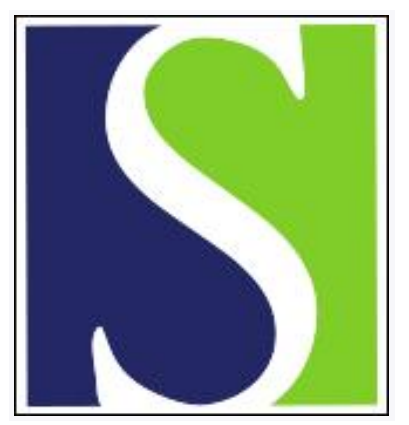

Scand J Work Environ Health 2008;34(5):337-344

https://doi.org/10.5271/sjweh.1280

Published online: 14 Oct 2008, Issue date: 00 Oct 2008

Workplace observation of work stressors, catecholamines and musculoskeletal pain among male employees

by Elfering A, Grebner S, Gerber H, Semmer NK

Affiliation: Department of Psychology, University of Bern, Muesmattstr 45, 3000 Bern 9, Switzerland. achim.elfering@psy.unibe.ch

Refers to the following text of the Journal: 2002;28(6):386-393

The following articles refer to this text: 2008;34(5):323-325;

2013;39(3):310-318

Key terms: catecholamines; employee; male employee; man; musculoskeletal pain; norepinephrine; observation; recovery; unwinding; work stressor; workplace; workplace observation

This article in PubMed: www.ncbi.nlm.nih.gov/pubmed/18853065

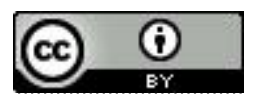




\title{
Workplace observation of work stressors, catecholamines and musculoskeletal pain among male employees
}

\author{
by Achim Elfering, PhD, , 2 Simone Grebner, PhD, 1, 3 Hans Gerber, MD,, ${ }^{4,}$ Norbert K Semmer, PhD ${ }^{1,2}$
}

\begin{abstract}
Elfering A, Grebner S, Gerber H, Semmer NK. Workplace observation of work stressors, catecholamines and musculoskeletal pain among male employees. Scand J Work Environ Health 2008;34(5):337-344.

Objectives Prolonged activation of the sympathetic-adrenal medullary system during work and the lack of recovery after work may indicate a risk for musculoskeletal pain (ie, neck, shoulder, or low-back pain). This field study tested whether a high level of work stressors is associated with musculoskeletal pain and higher urinary norepinephrine excretion rates at work, after work, and on Sundays.

Methods Altogether 32 male employees working in adult education took part in a three-phase repeated-measures field study including workplace observation, self-report of musculoskeletal pain, and measurement of urinary catecholamine at work, in the evening after work, and at corresponding times on Sundays.

Results In univariate analyses, work stressors and workday levels of norepinephrine were significantly higher in the participants with high levels of musculoskeletal pain. Moreover, regressing workday norepinephrine excretion rates on predictor variables in the multilevel regression analysis showed a significant interaction between work stressors and musculoskeletal pain $(\mathrm{P}=0.011)$ with elevated excretion rates of norepinephrine in those exposed to a high level of work stressors and, at the same time, reporting higher levels of musculoskeletal pain.

Conclusions High levels of work stressors turned out to be associated with musculoskeletal pain and norepinephrine concentration in male employees. Increased activity of the sympathetic-adrenal medullary system seems to play an important role in work-related musculoskeletal pain.
\end{abstract}

Key terms norepinephrine, recovery, unwinding.

Most work-related musculoskeletal disorders have a complex and multifactorial etiology. Among other factors, biomechanical load, psychosocial stress, health behavior, and pain-related cognition are assumed to play an important role in the development of persisting musculoskeletal pain (1). Our field study tests whether catecholamine release constitutes an important link between adverse psychosocial factors at work (ie, work stressors such as time pressure and performance constraints) and musculoskeletal pain.

Reaction to work stressors leads to a catabolic state of hypervigilance, in which energy is provided so that the worker can cope with the stressors. The stress response is characterized by activation of the sympathetic-adrenal medullary system, including catecholamine secretion leading to increased heart rate and blood pressure. Moreover, activation of the sympathetic-adrenal medullary system leads to secretion of norepinephrine, which heightens muscle activity because of an increased sensitivity of the synapses and by recruiting more muscle fibers when an activity is performed (2). With regard to the activation of muscles, epinephrine amplifies the effects of norepinephrine. Studies by Lundberg and his coworker show that both mental stress and physical load elevate electromyographic (EMG) activity (3-5). Thus mental stressors can elevate the sympathetic-adrenal medullary system and EMG activity even in the absence of heavy physical load or unfavorable posture (3-5). It is noteworthy that mental stress can persist after work is over and prevent relaxation and the recovery of muscles (3). We therefore think that the effects of both physical and mental load at work and after work should be considered, which is in accordance with current models on occupational musculoskeletal pain, such as the "Brussels

1 Department of Psychology, University of Bern, Bern, Switzerland.

2 National Centre of Competence in Research, Affective Sciences, University of Geneva, CISA, Geneva, Switzerland.

3 Central Michigan University, Mount Pleasant, Michigan, United States.

4 Institute of Clinical Chemistry, University of Bern, Bern, Switzerland.

5 Surgeon general of the canton Bern, Bern, Switzerland.

Correspondence to: Achim Elfering, Department of Psychology, University of Bern, Muesmattstr 45, 3000 Bern 9, Switzerland. [E-mail: achim.elfering@psy.unibe.ch] 
model" (6), the Neuromotor Noise Theory (7), and the "Cinderella model" (8). With respect to catecholamines, both epinephrine and norepinephrine should be related to musculoskeletal pain. However, norepinephrine is more proximally linked to muscle activity and musculoskeletal pain than epinephrine is (10). Altogether, evidence is increasing that chronic work-related stress, lack of rest, and recovery after work contribute to the development of persistent musculoskeletal pain (5). Nevertheless, there is still a lack of field studies assessing work characteristics, musculoskeletal pain, and catecholamine excretion rates, both at work and after work (10).

\section{Hypotheses}

In our study, we expected higher musculoskeletal pain in the participants to correspond with higher levels of stressors at work (hypothesis 1). Moreover, we expected work stressors to be positively associated with the excretion rates of urinary catecholamines at work (hypothesis 2). Furthermore, we expected an interaction between stressors at work and musculoskeletal pain. Specifically, we expected comparably higher levels of norepinephrine at work (hypothesis 3a) and in the evening after work (hypothesis $3 b$ ) in the participants who reported high levels of musculoskeletal pain and, at the same time, were exposed to higher levels of stressors at work. The urinary excretion rates of norepinephrine for those who reported less musculoskeletal pain and had high levels of stressors, or reported musculoskeletal pain while having low levels of stressors at work, should have been considerably lower. Finally, we expected those who reported higher musculoskeletal pain and, at the same time, had higher levels of stressors at work to show less of a reduction in their norepinephrine levels from a workday to Sunday than the others did (hypothesis 4).

\section{Study population and methods}

\section{Study population}

The sample consisted of 39 healthy male instructors from a public service organization in Switzerland. The participation rate among all of the employees of the organization was $60 \%$. Altogether 35 of 39 persons agreed to the repeated measurements of urinary catecholamines. Three had to be excluded from the data analyses for being on medication. The mean age of the final sample of 32 male employees was 43.8 (SD 8.3, range 32-58) years. More than half of the sample $(\mathrm{N}=17)$ had a university degree, and all but one had completed vocational training. All of the participants were full-time employees and had held their present position for at least 2 (mean 5.6, SD 1.9) years. A total of 6 of the 32 employees had supervisory positions. Most of the participants were married $(\mathrm{N}=26)$ and had children $(\mathrm{N}=28)$.

\section{Measures}

Smoking was assessed as the number of cigarettes smoked on the day of measurement, recorded in a diary in the evening of the day. The body mass index (BMI) was calculated by taking a person's body weight and dividing it by their body height squared. Body height was reported by the participants, and body weight was measured on a weight scale.

\section{Work characteristics}

The work conditions were rated by trained observers using a short version of the Instrument for Stress Oriented Task Analysis (ISTA) (11). The observers were trained for 7.5 days (12). The trainees were a research assistant, two student assistants, and five students serving a research internship for advanced psychology students. The training started with a study of the literature on task analysis, information about the occupation under study, psychological methods of observation, and bias in observation. The tasks of the trainees included self observation, interviews, and observation-based ratings. The training ended with a comprehension and memory test of the rating instrument and its dimensions.

Each participant's work conditions were rated by two observers, and both ratings were averaged to reduce potential bias in the ratings. All of the items had a 5-point Likert format, reflecting either the intensity or the frequency of work stressors and job control. Job control was measured by four items, two of which covered method control ("employee decides which way to carry out his work" and "employee individually plans his work"), and the other two referred to time control (2 items: employee disposes his workday and work schedule" and "employee assigns his daily workhours"). Cronbach's alpha for job control was 0.81 . Task-related stressors were measured by time pressure ( 1 item: "employee works longer because of having too much work to do"), performance constraints (1 item: "employee has to work with inadequate devices or obsolete information"), uncertainty (1 item: "employee is in a situation in which he cannot go on with work because of a problem in another area"), and work interruptions (2 items "employee must work at several tasks simultaneously and must jump back and forth between tasks" and "employee is interrupted by telephone calls"). For a composite measure of task-related job stressors, the five-stressor items were averaged. [See the report by Grebner et al (13) for the same procedure with the questionnaire version of the 
instrument.] This index of work stressors represents a heterogeneous concept, consisting of items from scales that are correlated yet do not represent a homogeneous construct. For such an index, the composite score reliability (14) is the appropriate reliability estimate. Its value was $r=0.82$.

\section{Musculoskeletal pain}

Musculoskeletal pain was assessed as pain in the neck, the shoulder region, and the lower back in the last 12 months [never (1), less than monthly (2), less than weekly (3), less than daily (4), daily (5)]. These three items are part of a scale measuring psychosomatic complaints developed by Mohr (15), based on Fahrenberg (16). The Cronbach alpha for musculoskeletal pain was 0.85 , the values ranging from 3 to 15 .

\section{Domestic work}

Three items addressed domestic work. The items were reported every evening at 2100 , along with the time (hours and minutes) spent doing household chores, child care, and caring for relatives. A sum index of all three items indicated the total domestic workload in terms of industrial hours (Ih $=$ hours + minutes/60, expressing minutes within the decimal system (ie, 3 hours 15 minutes equals 3.25 ). It was calculated separately for domestic work in the evening of the workdays and on Sundays.

\section{Catecholamine measures}

The participants were instructed to empty their bladder in the morning at 0715 . These specimens were not analyzed, however. The participants were asked to note the time when they voided their bladder until noon. Urinary catecholamine samples were collected at work before lunch (1200), before the end of work (1700), and in the evening (2100) by trained collectors. The measurements were repeated at home on Sunday at corresponding times. On each of three workdays and three Sundays more than $75 \%$ of the sample covered the whole time period; that is, $75 \%$ of the participants did not empty their bladder between measurements. Only two or three persons had collection periods that were shorter than 2 hours. For the afternoon period, more than $70 \%$ of the measurements covered the whole time period, and, for the evening period, approximately $80 \%$ of the measurements covered the whole time period. On Sunday, the participants were asked to avoid vigorous physical activity (such as sports, housework, or gardening) or demanding mental work in order to obtain valid physiological reference values. The participants were asked to empty their bladder at the time indicated, measure the volume of urine with a metering box, and keep a record of each voiding time and volume that occurred between the measurement points. The urine samples $(100 \mathrm{ml})$ were acidified immediately by hydrochloric acid $(\mathrm{HCl})$ to a $\mathrm{pH}$ of 3 . Each sample was then divided into two aliquots of $15 \mathrm{ml}$ each. The aliquots were stored in a freezer $\left(-20^{\circ} \mathrm{C}\right)$ until the laboratory analysis. The excretion rates of epinephrine and norepinephrine were expressed as $\mathrm{pmol} /\left(\mathrm{min} \times \mathrm{kg}\right.$ ) [picomole, $10^{-12}$ moles per liter of urine/(minutes since last voiding $\times$ kilograms of body weight)]. The participants recorded their consumption of alcohol, nicotine and caffeine and their intake of medication in a diary each evening. The accuracy and robustness of the measurements with respect to the collection schedule, acidification, storing conditions, and comparison of the time-related index with the ratio of creatinine was tested by the authors in a previous experimental study (17).

\section{Laboratory analysis}

The aliquots were analyzed in the Chemical Laboratory of the University Hospital in Bern by high-pressure liquid chromatography. More details on the laboratory analysis, including information on accuracy, have been reported elsewhere (17)

\section{Design}

The study had a repeated measures design with respect to the catecholamine assessments. Catecholamine data were collected on a workday (Tuesday, Wednesday, or Thursday) and on the following Sunday within the same week. The data collection was repeated twice, so that 3 weeks were covered for each person. The time lag between the measurements was 6 weeks. Therefore, each participant had up to 18 urinary catecholamine measurements ( 3 workdays plus 3 Sunday measures for 3 weeks). In the first week, there were no missing data. One person could not take part in the second and third week. Due to situational constraints of the participants, 1 single measurement was skipped in the second week and 13 were skipped in the third week. Three further measurements ( 1 in the second week and 2 in the third week) were lost due to failed laboratory analyses. Altogether, 278 workday catecholamine measurements and 270 Sunday catecholamine measurements were analyzed. There was no imputation of missing values.

\section{Data analysis}

The univariate analysis included a comparison of work conditions and urinary excretion rates of catecholamine between a low (below or equal the median value of musculoskeletal pain) and a high (higher than the median 
value of musculoskeletal pain) subgroup of participants (hypothesis 1). In the univariate analyses, the day- and time-corresponding measurements of norepinephrine and epinephrine were averaged for each person to control for day-specific situational influences on the urinary excretion rates of catecholamine [ie, measures of the same time and type of day were averaged for each person; for instance, the three workday noon measurements from the three workweeks were averaged, the three workday measurements made at 1700 were averaged, etc.; for a similar approach used for the cortisol measurements, see the report of Pruessner et al (18)]. To test hypothesis 1, Student's t-test for group comparisons was calculated. In order to test hypothesis 2 , we calculated the correlations between the work stressors and the catecholamine levels. P-values were one-tailed with the alpha set to $5 \%$.

Hypotheses 3 and 4 were tested with a multilevel analysis (19), in which the catecholamine measurements were regressed on predictor variables with two hierarchical levels, namely, catecholamine measurements (level 1) nested within persons (level 2). We used the MLwiN software package (20). The dependent variables were the excretion rates of norepinephrine and epinephrine. The predictor variables that were assessed for level 1 were type of day (workday or Sunday), week (first, second, or third), total time spent on household chores, child care or care of relatives, and time of day (measurement at 1200,1700 , or 2100). The level-2 predictor variables were person-related (age, BMI, smoking, work stressor index, job control, and musculoskeletal pain). All of the predictor variables in the multilevel analyses were centered around the grand mean (19). All of the P-values in the multilevel regression analysis were one-tailed with the alpha set at $5 \%$.

\section{Results}

\section{Prevalence of musculoskeletal pain}

The participants' reports of the 1-year prevalence of neck, shoulder, and low-back pain showed that most of the respondents experienced musculoskeletal pain. Only $15.6 \%$ reported "never" having experienced low-back pain (scored 1); this percentage was higher for neck pain $(37.5 \%)$ and shoulder pain $(43.8 \%)$. Half of the participants reported low-back pain "less than monthly" (scored 2), and this percentage was a bit lower for neck pain and shoulder pain (both 31.3\%). The figures for the three different types of pain did not differ much for the participants who reported more frequent pain ("less than weekly", scored 3: $21.9 \%$ with neck pain, $12.5 \%$ with shoulder pain, $18.8 \%$ with low-back pain; "less than daily", scored 4: $6.2 \%$ with neck pain, $6.2 \%$ with shoulder pain, $9.4 \%$ with low-back pain; and "daily", scored 5: $3.1 \%$ with neck pain, $6.2 \%$ with shoulder pain, $6.2 \%$ with low-back pain). Neck, shoulder, and low-back pain correlated with one another. Neck and shoulder pain were more closely related with one another $(r=0.780)$ than neck pain with low-back pain $(r=0.620)$ and shoulder pain with low-back pain $(r=0.580)$. However, these differences in the strength of the association were not significant $[\mathrm{P}=0.136$ and $\mathrm{P}=0.059$, test of correlated correlations according to Williams (21)]. The overall sum of musculoskeletal pain ranged from 3 to 15 , with half of the participants scoring 5 or less, representing the "low musculoskeletal pain" group. In the "high musculoskeletal pain" group, seven participants had a score of 6, one had a score of 7 , four scored 9 , and four scored relatively high at $11,12,13$, and 15 .

\section{Work stressors in the groups with low and high mus- culoskeletal pain}

Table 1 shows the comparison between the groups with low and high musculoskeletal pain with respect to the study variables. The groups did not differ significantly with regard to age, smoking habits, or body weight. In line with expectations (hypothesis 1), the "high musculoskeletal pain" group revealed higher scores for work stressors $(\mathrm{P}=0.033)$. However, against expectations, the "high musculoskeletal pain" group also had higher levels of job control. The norepinephrine excretion rates at work were higher among those with high musculoskeletal pain than among those with low musculoskeletal pain, and the group differences reached statistical significance at noon $(\mathrm{P}=0.015)$ and at the end of the workday $(\mathrm{P}=0.047)$.

The workday epinephrine excretion rates were also higher in the "high musculoskeletal pain" group at the end of the workday $(\mathrm{P}=0.050)$. However, there was no corresponding pattern for group differences in the evening of workdays and on Sundays. The mean Sunday urinary excretion rates of both epinephrine and norepinephrine at 1200, 1700, and 2100 in the "high musculoskeletal pain" group did not differ from those of the "low musculoskeletal pain" group or were smaller. Furthermore, the groups did not differ in the time spent on household chores, child care, or care of relatives.

\section{Correlation between work stressors and catechol- amines on a workday}

The correlations between workday norepinephrine and work stressors were positive, and they reached statistical significance for the norepinephrine measures at 1200 $(\mathrm{r}=0.297, \mathrm{P}=0.049)$ and at $2100(\mathrm{r}=0.332, \mathrm{P}=0.032)$. The correlations between workday epinephrine and work stressors were all positive ( $r=0.113$ to $r=0.134$ ), but did not reach statistical significance. There were 
Table 1. Mean values and standard deviations of the study variables for the groups with low and high musculoskeletal pain.

\begin{tabular}{|c|c|c|c|c|c|c|}
\hline \multirow[t]{3}{*}{ Variable } & \multicolumn{6}{|c|}{ Musculoskeletal pain } \\
\hline & \multicolumn{2}{|c|}{ Low $(\mathrm{N}=16)$} & \multicolumn{4}{|c|}{ High $(\mathrm{N}=16)$} \\
\hline & Mean & SD & Mean & SD & $\mathrm{t}$ & $\begin{array}{l}\text { P-value } \\
\text { (one } \\
\text { tailed) }\end{array}$ \\
\hline Age & 43.630 & 8.823 & 44.000 & 7.967 & -0.126 & 0.800 \\
\hline $\begin{array}{l}\text { Body mass } \\
\text { index }\left(\mathrm{kg} / \mathrm{kg}^{2}\right)\end{array}$ & 24.820 & 3.362 & 26.056 & 2.068 & -1.252 & 0.111 \\
\hline Smoking ${ }^{\mathrm{b}}$ & 0.125 & 0.342 & 0.188 & 0.403 & -0.473 & 0.320 \\
\hline $\begin{array}{l}\text { Work stressors (work } \\
\text { place observation) }\end{array}$ & 2.263 & 0.637 & 2.681 & 0.601 & -1.913 & 30.033 \\
\hline $\begin{array}{l}\text { Job control (work- } \\
\text { place observation) }\end{array}$ & 2.547 & 0.666 & 3.008 & 0.673 & -1.947 & $0.969^{\circ}$ \\
\hline $\begin{array}{l}\text { Domestic work after } \\
\text { regular work (house- } \\
\text { work, child care, } \\
\text { caring for relatives) }\end{array}$ & 1.869 & 2.171 & 1.864 & 2.164 & 0.006 & 0.990 \\
\hline $\begin{array}{l}\text { Domestic work on } \\
\text { Sundays (housework, } \\
\text { child care, caring for } \\
\text { relatives) }\end{array}$ & 3.536 & 4.235 & 4.244 & 4.773 & -0.444 & 0.330 \\
\hline Norepinephrine on wo & orkdays & {$[\mathrm{pmol} /(\mathrm{I}$} & in $\times \mathrm{kg}$ )] & & & \\
\hline $\begin{array}{l}\text { Noon } \\
\text { End of work } \\
\text { Evening }\end{array}$ & $\begin{array}{l}3.086 \\
2.970 \\
3.212\end{array}$ & $\begin{array}{l}1.076 \\
0.944 \\
1.182\end{array}$ & $\begin{array}{l}3.994 \\
3.684 \\
3.489\end{array}$ & $\begin{array}{l}1.181 \\
1.350 \\
1.099\end{array}$ & $\begin{array}{l}-2.273 \\
-1.736 \\
-0.688\end{array}$ & $\begin{array}{l}0.015 \\
0.047 \\
0.249\end{array}$ \\
\hline Epinephrine on workd & days [pm & $101 /(\min$ & $\mathrm{kg})]$ & & & \\
\hline $\begin{array}{l}\text { Noon } \\
\text { End of work } \\
\text { Evening }\end{array}$ & $\begin{array}{l}0.996 \\
0.754 \\
0.891\end{array}$ & $\begin{array}{l}0.651 \\
0.345 \\
0.373\end{array}$ & $\begin{array}{l}1.219 \\
0.967 \\
0.664\end{array}$ & $\begin{array}{l}0.414 \\
0.363 \\
0.215\end{array}$ & $\begin{array}{c}-1.156 \\
-1.700 \\
2.102\end{array}$ & $\begin{array}{l}0.129 \\
0.050 \\
0.977^{\circ}\end{array}$ \\
\hline Norepinephrine on Su & unday [pr & $\mathrm{mol} /(\mathrm{mi}$ & $\times \mathrm{kg})]$ & & & \\
\hline $\begin{array}{l}\text { Noon } \\
\text { Afternoon } \\
\text { Evening }\end{array}$ & $\begin{array}{l}2.862 \\
2.675 \\
2.833\end{array}$ & $\begin{array}{l}1.051 \\
1.367 \\
1.080\end{array}$ & $\begin{array}{l}2.906 \\
2.106 \\
2.373\end{array}$ & $\begin{array}{l}1.057 \\
0.756 \\
0.741\end{array}$ & $\begin{array}{c}-0.119 \\
1.456 \\
1.405\end{array}$ & $\begin{array}{l}0.453 \\
0.920^{\circ} \\
0.915\end{array}$ \\
\hline Epinephrine on Sunda & ay [pmol & $/(\min x$ & & & & \\
\hline $\begin{array}{l}\text { Noon } \\
\text { Afternoon } \\
\text { Evening }\end{array}$ & $\begin{array}{l}0.629 \\
0.556 \\
0.608\end{array}$ & $\begin{array}{l}0.261 \\
0.225 \\
0.249\end{array}$ & $\begin{array}{l}0.557 \\
0.433 \\
0.585\end{array}$ & $\begin{array}{l}0.263 \\
0.186 \\
0.302\end{array}$ & $\begin{array}{l}0.775 \\
1.826 \\
0.231\end{array}$ & $\begin{array}{l}0.778 \\
0.961^{\circ} \\
0.590\end{array}$ \\
\hline
\end{tabular}

a P-values from one-tailed hypothesis tests.

b Smoking indicates nonsmoking $(0=$ cigarettes/day) versus smoking ( 1 $=>1$ cigarette/day).

${ }^{c}$ We expected job control to be lower in the group with a high level of musculoskeletal pain, but indeed it turned out to be higher. For job control and other marked indicators the expectation was directional, and the onetailed P-value reflects the finding that our expectations were wrong.

${ }^{d}$ Corrected for unequal variances.

no significant associations between workday catecholamines and job control.

\section{Workday excretion rates of catecholamines of those who reported high musculoskeletal pain and had high levels of work stressors}

Table 2 shows the regression of workday norepinephrine and epinephrine excretion rates with respect to individual characteristics and work conditions. Smoking and musculoskeletal pain were significantly related to higher excretion rates of workday norepinephrine and epinephrine. In accordance with hypothesis $3 \mathrm{a}$, a
Table 2. Multilevel analysis of norepinephrine and epinephrine excretion rates on workdays (noon, end of work, evening). ${ }^{a}$ (parameter $=$ fixed parameter estimates, $\mathrm{SE}=$ standard error, random effects $=$ variance and covariance estimates of parameters that are allowed to vary on level 2, VAR = variances, IGLS = Iterative Generalized Least Squares)

\begin{tabular}{|c|c|c|c|c|}
\hline \multicolumn{3}{|c|}{ Norepinephrine } & \multicolumn{2}{|c|}{ Epinephrine } \\
\hline Parameter & SE & $\begin{array}{c}\text { P- } \\
\text { value }^{b}\end{array}$ & Parameter SE & $\begin{array}{c}\mathrm{P}- \\
\text { value }^{\mathrm{b}}\end{array}$ \\
\hline
\end{tabular}

Level-2 predictor variables (person)

\begin{tabular}{|c|c|c|c|c|c|}
\hline Age & 0.034 & 0.0170 .025 & 0.001 & 0.007 & 0.469 \\
\hline Smoking ${ }^{c}$ & 0.030 & 0.0110 .003 & 0.004 & 0.005 & 0.176 \\
\hline Work stressors & 0.244 & 0.3980 .269 & 0.201 & 0.163 & 0.109 \\
\hline Work control & 0.286 & 0.2620 .138 & -0.048 & 0.108 & 0.328 \\
\hline Musculoskeletal pain & 0.267 & $0.083<0.001$ & 0.083 & 0.034 & 0.007 \\
\hline $\begin{array}{l}\text { Work stressors } \times \\
\text { musculoskeletal pain }\end{array}$ & 0.440 & 0.1910 .011 & 0.095 & 0.078 & 0.112 \\
\hline \multicolumn{6}{|c|}{ Level-1 predictor variables (measurement) } \\
\hline Domestic work & 0.005 & 0.1100 .484 & -0.013 & 0.045 & 0.386 \\
\hline Time of $d$ & -0.190 & 0.0830 .022 & -0.148 & 0.034 & \\
\hline Workweek 1 & 0.387 & 0.1660 .009 & -0.034 & 0.068 & \\
\hline Workweek 2 & 0.235 & 0.1700 .083 & 0.070 & 0.069 & \\
\hline $\begin{array}{l}\text { Work stressors } \times \\
\text { time of day }\end{array}$ & -0.077 & $0.138 \quad 0.287$ & -0.059 & 0.056 & 0.147 \\
\hline $\begin{array}{l}\text { Musculoskeletal } \\
\text { pain } \times \text { time of day }\end{array}$ & -0.082 & 0.0320 .006 & -0.037 & 0.013 & 0.003 \\
\hline $\begin{array}{l}\text { Work stressors } \times \\
\text { musculoskeletal } \\
\text { pain } \times \text { time of day }\end{array}$ & -0.092 & $0.074 \quad 0.108$ & -0.048 & 0.030 & 0.068 \\
\hline \multicolumn{6}{|l|}{ Random effects } \\
\hline Intercept & 2.895 & 0.173 & 0.857 & 0.071 & \\
\hline VAR intercept Level 2 & 0.352 & 0.125 & 0.060 & 0.021 & \\
\hline VAR intercept Level 1 & 1.251 & 0.113 & 0.208 & 0.019 & \\
\hline 2×log likelihood (IGLS) & 881.170 & & 387.146 & & \\
\hline
\end{tabular}

a Sample size: $\mathrm{N}=275$ (norepinephrine), $\mathrm{N}=274$ (epinephrine) measurements from 32 participants.

${ }^{b}$ One-tailed Wald Test (parameter estimates/standard error). The Wald Test is one-tailed for variances (VAR).

c Smoking indicates the number of cigarettes smoked on the measurement day.

significant interaction between work stressors and musculoskeletal pain indicated that increased excretion rates of norepinephrine were restricted to the participants who reported musculoskeletal pain and were also being exposed to high levels of work stressors $(\mathrm{P}=0.011)$. Figure 1 shows that the norepinephrine excretion rates of the other participants were lower and similar.

There was no corresponding interaction effect for the epinephrine excretion rates. The excretion rates of catecholamines slightly decreased with the time of day, but this decrease was restricted to those with a high level of musculoskeletal pain. Contrary to hypothesis $3 \mathrm{~b}$, the participants who reported musculoskeletal pain and were also exposed to a high level of work stressors did not show persisting higher urinary excretion rates of norepinephrine after work. The proposed three-way interaction between work stressors, musculoskeletal pain, and time of day was not statistically significant. 


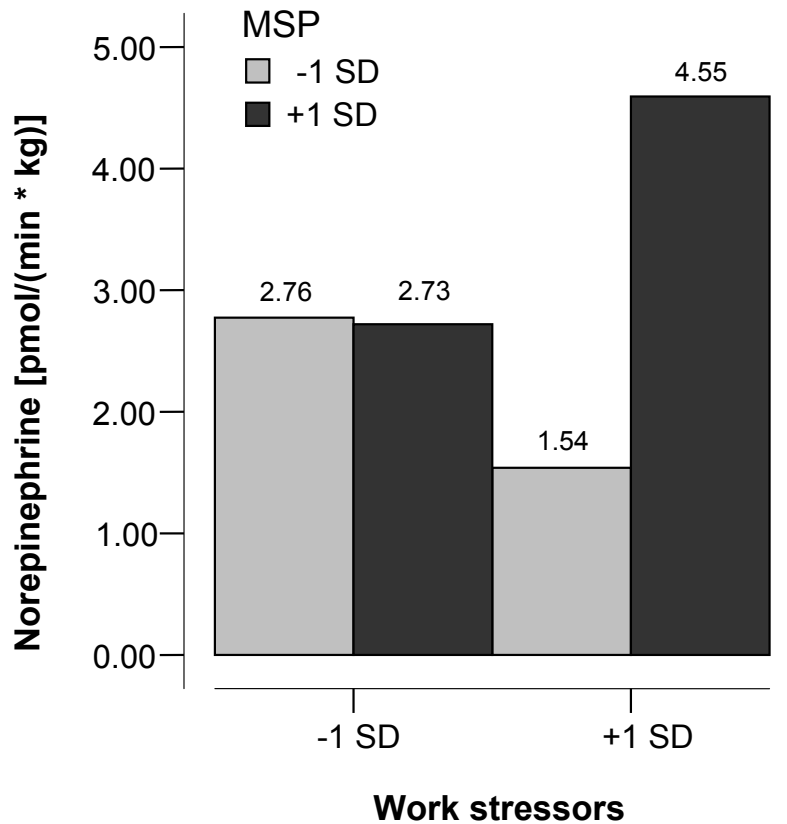

Figure 1. Interaction between work stressors and musculoskeletal pain (MSP) with respect to workday urinary norepinephrine.

\section{Sunday excretion rates of catecholamines among those who reported a high level of musculoskeletal pain and had high levels of work stressors}

The regression of workday and Sunday catecholamines with respect to the predictor variables yielded a significant effect for day, indicating that the urinary excretion rates of catecholamine were significantly higher on workdays than on Sundays (table 3). They were also higher at 1200 than at 1700 . Age and smoking were significantly positively related to higher excretion rates of norepinephrine. Contrary to hypothesis 4 , the participants who reported musculoskeletal pain while being exposed to a high level of work stressors did not show persistently higher urinary excretion rates of norepinephrine on Sunday. There was no significant prediction according to musculoskeletal pain or work factors, nor was there an interaction between these variables.

\section{Discussion}

Many researchers in occupational health sciences recommend measuring risk factors and dependent variables with different methods $(22,23)$. This study included an observational assessment of work conditions and found associations between work stressors and musculoskeletal pain. There are only a few other studies that had done so earlier (24). Therefore, this study contributes to the increasing evidence that it is not only people's
Table 3. Multilevel analysis of norepinephrine and epinephrine during work (noon, end of work) and corresponding times on Sundays. ${ }^{\text {a }}$ (parameter $=$ fixed parameter estimates, $S E=$ standard error, random effects = variance and covariance estimates of parameters that are allowed to vary on level 2, VAR = variances, IGLS = Iterative Generalized Least Squares)

\begin{tabular}{|c|c|c|c|c|c|}
\hline & \multicolumn{2}{|c|}{ Norepinephrine } & \multicolumn{3}{|c|}{ Epinephrine } \\
\hline & Parameter SE & $\begin{array}{c}\mathrm{P}- \\
\text { value }^{\mathrm{b}}\end{array}$ & Paramete & er SE & $\begin{array}{c}\text { P- } \\
\text { value }\end{array}$ \\
\hline \multicolumn{6}{|c|}{ Level-2 predictor variables (person) } \\
\hline Age & $0.025 \quad 0.012$ & 0.017 & -0.002 & 0.004 & 0.312 \\
\hline Smoking ${ }^{c}$ & 0.0230 .008 & 0.002 & 0.002 & 0.003 & 0.203 \\
\hline Work stressors & $0.285 \quad 0.337$ & 0.199 & 0.008 & 0.120 & 0.475 \\
\hline Work control & $0.254 \quad 0.187$ & 0.087 & -0.024 & 0.063 & 0.650 \\
\hline Musculoskeletal pain & 0.1150 .073 & 0.057 & 0.031 & 0.026 & 0.475 \\
\hline $\begin{array}{l}\text { Work stressors } \times \\
\text { musculoskeletal pain }\end{array}$ & 0.2090 .167 & 0.106 & -0.029 & 0.060 & 0.313 \\
\hline \multicolumn{6}{|c|}{ Level-1 predictor variables (measurement) } \\
\hline $\begin{array}{l}\text { Domestic work } \\
\text { Day (1 = workday, }\end{array}$ & 0.0580 .039 & 0.070 & -0.013 & 0.014 & 0.177 \\
\hline $2=$ Sunday) & -0.8640 .113 & $<0.001$ & -0.290 & 0.041 & $<0.001$ \\
\hline Time of day & -3.1640 .334 & $<0.001$ & -1.114 & 0.122 & $<0.001$ \\
\hline Workweek 1 & 0.3810 .133 & 0.002 & -0.067 & 0.049 & 0.084 \\
\hline Workweek 2 & $0.206 \quad 0.135$ & 0.153 & -0.028 & 0.049 & 0.287 \\
\hline Work stressors $\times$ day & -0.3680 .183 & 0.022 & 0.031 & 0.067 & 0.319 \\
\hline $\begin{array}{l}\text { Musculoskeletal pain } \times \\
\text { day } \\
\text { Work stressors } \times\end{array}$ & $-0.047 \quad 0.042$ & 0.134 & -0.026 & 0.015 & 0.044 \\
\hline $\begin{array}{l}\text { musculoskeletal pain } \times \\
\text { day }\end{array}$ & $-0.077 \quad 0.098$ & 0.218 & 0.005 & 0.036 & 0.441 \\
\hline \multicolumn{6}{|l|}{ Random effects } \\
\hline Intercept & $3.396 \quad 0.253$ & & 1.120 & 0.092 & \\
\hline VAR intercept level 2 & 0.0330 .012 & & 0.003 & 0.001 & \\
\hline VAR intercept level 1 & $0.184 \quad 0.014$ & & 0.025 & 0.002 & \\
\hline $2 \times \log$ likelihood (IGLS) & 1087.052 & & 358.067 & & \\
\hline
\end{tabular}

a Sample size: $\mathrm{N}=358$ (norepinephrine), 357 (epinephrine) measurements from 32 participants.

${ }^{b}$ One-tailed significance level of the Wald test (parameter estimates/standard error). The Wald test is one-tailed for variances (VAR).

c Smoking indicates the number of cigarettes smoked on measurement days.

perception of psychosocial risk factors that is related to musculoskeletal pain, but also their work conditions as assessed by independent raters. Moreover, work stressors were related to the excretion rates of catecholamine and musculoskeletal disorders, associations that are in accordance with current models of occupational musculoskeletal pain. Work stressors-for example, time pressure-lead to a mobilization of resources. A mobilization of resources corresponds with physiological responses, including increased activation of the sympathetic-adrenal medullary system. While this activation is useful in a normal range, two deviations from "normal" may occur. The first deviation refers to excretion rates that are too high during demanding situations, that is, reactivity is too high. The second deviation refers to impaired recovery, that is, a prolonged response that takes too long to return to normal (or, possibly, never gets back to normal excretion rates). These two deviations 
from normal functioning of the sympathetic-adrenal medullary system are, of course, not mutually exclusive-one can have both, reactivity that is too high and impaired unwinding. Both processes may lead to higher excretion rates of urinary catecholamines, and such a situation has been shown to correspond to mortality among the elderly (25). The results of our current study showed that the activity of the sympathetic-adrenal medullary system and work stressors were higher among the employees who reported musculoskeletal pain more frequently.

Research on stress at work shows that elevated norepinephrine levels in urine predominantly characterize the mobilization of physical resources (26). When the situation mainly requires an activation of mental resources, predominantly epinephrine is activated. Depending on the remaining resources of the person, an elevation of epinephrine may correlate with feelings of activation or, in case of depleted resources, with feelings of anxiety and distress (27). With regard to the activation of muscles, however, mental load and physical load show synergistic effects (4). Indeed, synergistic effects of mental load and physical load have even been observed on the level of disc pressure (28). We, therefore, argue that the effects of physical load and mental load combine with regard to musculoskeletal pain, and their potential mediators, norepinephrine and epinephrine, combine as well. Thereby, we consider norepinephrine as more proximally linked to musculoskeletal pain through its more direct physiological effect on muscles. Nevertheless, even if norepinephrine is predominantly activated by physical load, and epinephrine by mental load, it seems likely that, in most stressful situations at work, both catecholamines will be elevated. In our study, the correlations showed a pattern that conforms to the view of norepinephrine as the more proximal link to musculoskeletal pain. Furthermore, norepinephrine was associated with work stressors. This finding is in line with the results of previous studies that showed a similar association between work conditions, musculoskeletal pain, and norepinephrine excretion $(3,10)$. Both sustained activation during work and lack of muscular relaxation after work may cause pain. The norepinephrine release during work was higher among those who reported pain and were exposed to a high level of work stressors at the same time. The excretion rates of norepinephrine and epinephrine were still elevated in the evening on workdays, but this difference was not significant. There was a tendency for a slightly lower norepinephrine excretion among those who were exposed to a high level of work stressors but did not report musculoskeletal pain. One might argue that these persons might be more resilient to stressors, cope more successfully with stressors, or show reactivity to stressors with a physiological system other than the sympathetic-adrenal medullary system (individual response specificity). Further studies should take into consideration these potential individual moderators. Contrary to hypothesis 4 , those with musculoskeletal pain and work stressors did not show impaired recovery during their days off. One explanation for the lack of differences in musculoskeletal pain in unwinding and recovery may have been the study design itself. The participants were instructed to avoid heavy work and sports in leisure time so that the urinary excretion rates of catecholamine would reflect unwinding and recovery after work. Therefore, the comparably little workload during leisure time from household chores, child care, and caring for relatives may not be representative of the daily life of the participants. The norepinephrine levels at work were comparable with Danish reference values of urinary epinephrine and norepinephrine for 120 Danish healthy persons performing their routine work (29). For norepinephrine, geometric mean levels, expressed as micromoles per mole of creatinine, for a time window from 1530 to 1830 was 24.2 and the range was 8.5-67.1. The respective norepinephrine values in our study, expressed as micromoles per mole of creatinine, at 1700 was 26.11 , and the respective range was 13.9-52.9. Therefore, the norepinephrine levels (and also epinephrine excretion) were highly comparable with the Danish reference values.

The job demand-control model (30) postulates that job control attenuates the effects of job demands on health and well-being. In this study we found no preventive effect of job control, nor a buffering effect of job control on the influence of work demands. The study even showed, unexpectedly, a higher level of observed job control among those reporting more musculoskeletal pain. Meier et al (31) recently found that job control attenuated the effects of stressors on musculoskeletal pain only for people with an internal locus of control. For people with an external locus of control, job control actually predicted more pain as stressors increased. In our study, locus of control was not assessed, but it is possible that the participants suffering from musculoskeletal pain had a more external locus of control, interfered by the effects of job control. The small sample size and the sample of healthy men with comparably well-designed jobs limit the generalizability of the study results. Therefore, there is a need for replication. On the other hand, the multimethod and repeated measures approach rules out sources of bias that weaken the conclusions that can be drawn from many other studies. This study, therefore, adds plausibility to an important possible psychobiological mechanism that links psychosocial work conditions to musculoskeletal disorders. Against the background of increasing time pressure for many employees (32), this study furthermore promotes the redesign of jobs as a way of preventing musculoskeletal disease. 


\section{Acknowledgments}

The research reported in this article was supported by a grant from the Migros-Kulturstiftung to Simone Grebner and Norbert Semmer.

\section{References}

1. Waddell G, Burton AK. Occupational health guidelines for the management of low back pain at work: evidence review. Occup Med. 2001;51:124-35.

2. Westgaard RH. Effects of psychological demand and stress on neuromuscular function. In: Moon SD, Sauter SL, editors. Beyond biomechanics: psychosocial aspects of musculoskeletal disorders in office work. London: Taylor \& Francis; 1996. p 75-89.

3. Melin B, Lundberg U. A biopsychosocial approach to work-stress and musculoskeletal disorders. J Psychophysiol. 1997;11:238-47.

4. Lundberg U. Psychophysiology of work: stress, gender, endocrine response, and work-related upper extremity disorders. Am J Ind Med. 2002;41:383-92.

5. Lundberg U, Melin B. Stress in the development of musculoskeletal pain. In: Linton S, editor. Avenues for the prevention of chronic musculoskeletal pain and disability. Amsterdam: Elsevier; 2002. p 165-82.

6. Johansson H, Arendt-Nilsson L, Bergenheim M, Blair S, van Dieen J, Djupsjöbacka M, et al. Epilogue: an integrated model for chronic work-related myalgia "Brussels Model". In: Johansson H, Windhorst U, Djupsjöbacka M, Passatore M, editors. Chronic work-related myalgia: neuromuscular mechanisms behind work-related chronic muscle pain syndromes. Gävle (Sweden): University Press; 2003. p 291-300.

7. Van Galen GP, Müller MLTM, Meulenbroek RGJ, Van Gemmert AWA. Forearm EMG response activity during motor performance in individuals prone to increased stress reactivity. Am J Ind Med. 2002;41:406-19.

8. Hägg GM. Human muscle fibre abnormalities related to occupational load. Eur J Appl Physiol. 2000;83:159-65.

9. Salamon E, Esch T, Stefano GB. Pain and relaxation [review]. Int J Mol Med. 2006;18:465-70.

10. Elfering A, Grebner S, Semmer NK, Gerber H. Time control, catecholamines, and back pain among young nurses. Scand J Work Environ Health. 2002;28(6):386-93.

11. Semmer, NK, Zapf D, \& Dunckel H. Assessing stress at work: a framework and an instrument. In: Svane O, Johansen C, editors. Work and health-scientific basis of progress in the working environment. Luxembourg: Office for Official Publications of the European Communities; 1995. p 105-113.

12. Grebner S. Stress at work, well-being, blood pressure, and Cortisol: Two longitudinal field-studies [dissertation]. Bern: University of Bern, 2001.

13. Grebner S, Semmer NK, Elfering A. Working conditions and three types of well-being: a longitudinal study with self-report and rating data. J Occup Health Psychol. 2005;10:31-43.

14. Nunnally JC, Bernstein IH. Psychometric theory. 3rd ed. New York (NY): McGraw-Hill; 1994.

15. Mohr G. Die Erfassung psychischer Befindensbeeinträchtigung bei Industriearbeitern [Assessment of strain in industrial workers]. Frankfurt: Lang; 1986.

16. Fahrenberg, J. Die Freiburger Beschwerdeliste FBL [The Freiburg Symptomlist]. Z Klin Psychol Psychother. 1975;4:49-100.

17. Elfering A, Grebner S, Semmer NK, Byland C, Gerber H. Two urinary catecholamine measurement indices for applied stress research: effects of time and temperature until freezing. Hum Factors. 2003;45:563-74.

18. Pruessner JC, Gaab J, Hellhammer DH, Lintz D, Schommer N, Kirschbaum C. Increasing correlations between personality traits and cortisol stress responses by data aggregation. Psychoneuroendocrinology. 1997;22:615-25.

19. Hox JJ. Multilevel analysis. Mahwah (NJ): Lawrence Erlbaum; 2002.

20. Rasbash J, Browne W, Goldstein H, Yang M, Plewis I, Healy $\mathrm{M}$, et al. A user's guide to MLwiN. London: Institute of Education, University of London; 2000.

21. Williams E J. The comparison of regression variables. J R Stat Soc Ser B. 1959;21:396-99.

22. Kasl SV, Jones BA. An epidemiological perspective on research design, measurement, and surveillance. In: Quick JC, Tetrick LE, editors. Handbook of occupational health psychology. Washington (DC): American Psychological Association; 2003:377-98.

23. Semmer NK, Grebner S, Elfering A. Beyond self-report: using observational, physiological, and event-based measures in research on occupational stress. In: Perrewé PL, Ganster DC, editors. Emotional and physiological processes and positive intervention strategies: research in occupational stress and well-being, vol. 3. Amsterdam: JAI Press; 2004:205-63.

24. Greiner BA, Krause N. Observational stress factors and musculoskeletal disorders in urban transit operators. J Occup Health Psychol. 2006;11:38-51.

25. Reuben DB, Talvi SLA, Rowe JW, Seeman TE. High urinary catecholamine excretion predicts mortality and functional decline in high-functioning, community-dwelling older persons. J Gerontol A Biol Sci Med Sci. 2000;55:618-24.

26. Mulder G, Mulder, LJM, Meijman TF, Veldman BP, van Roon AM. A psychophysiological approach to working conditions. In: Backs RW, Boucsein W, editors. Engineering psychophysiology: issues and applications. Mahwah (NJ): Lawrence Erlbaum; 2000. p 139-60.

27. Meijman T, Kompier M. Busy business: how urban bus drivers cope with time pressure, passengers, and traffic safety. J Occup Health Psychol. 1998;3:109-121.

28. Marras WS, Davis KG, Heaney CA, Maronitis AB, Allread WG. The influence of psychosocial stress, gender, and personality on mechanical loading of the lumbar spine. Spine. 2000;25:3045-54.

29. Hansen M, Garde AH, Christensen JM, Eller NH, Netterstrøm B. Reference intervals and variation for urinary epinephrine, norepinephrine and cortisol in healthy man and women in Denmark. Clin Chem Lab Med. 2001;39:842-9.

30. Karasek R. Job demands, job decision latitude, and mental strain. Adm Sci Q. 1979;24:285-311.

31. Meier LL, Semmer NK, Elfering A, Jacobshagen N. The double meaning of control: three-way interactions between internal resources, job control, and stressors at work. J Occup Health Psychol. 2008;13:244-58.

32. Kompier M. Dealing with workplace stress. In: Cooper CL, editor. Handbook of stress medicine and health. 2 nd ed. Boca Raton (CA): CRC; 2005. p 349-74.

Received for publication: 25 November 2007 